\title{
LC-MS (/MS) in Clinical Toxicology Screening Methods
}

\author{
Véronique Viette ${ }^{\mathrm{b}}$, Denis Hochstrasseracd, and Marc Fathi ${ }^{\star a d}$
}

\begin{abstract}
Toxicological screening is the analysis of biological samples to detect and identify unknown compounds. The high selectivity and sensitivity of liquid chromatography (LC) coupled to mass spectrometry (MS) or tandem mass spectrometry (MS/MS) technology provide an attractive alternative to the current methods (LC-UV, GC/MS, etc.). For these reasons, an increasing number of applications are being published. This paper is a brief overview of LC-MS(/MS) screening methods developed for clinical toxicology in recent years. Various sample treatments, chromatographic separations and detection by mass spectrometry can be combined to obtain screening methods adapted to the constraints and needs of clinical toxicology laboratories. Currently the techniques are in the hands of specialists, mainly in academic institutions. However, the evolution in technology should allow application of these techniques as a tool in toxicology laboratories, thus allowing a more widespread exploitation of their potential.
\end{abstract}

Keywords: Clinical toxicology $\cdot$ Identification $\cdot$ LC/MS · Screening

\section{Introduction}

Clinical laboratories are increasingly using LC-MS/MS technology for detection and identification of compounds in biological samples. The most frequently used samples in toxicology are blood (plasma, serum) and urine with the main analytes of interest being therapeutics drugs, drugs of abuse and toxic compounds. A good clinical method needs to be selective, accurate, sensitive, easy to use and automated. ${ }^{[1,2]}$ LC-MS combines high selectivity and sensitivity. Furthermore, this technique is compatible with a wide range of molecules.

An overview of different LC-MS (/MS) concepts employed in toxicological laboratories is proposed. Table 1 presents a list of screening method developments published between 2005 and 2011. This gives a summary of the main techniques with reference to sample clean-up, chromato-

\footnotetext{
${ }^{*}$ Correspondence: Dr. M. Fathi ${ }^{\mathrm{ad}}$

Tel.: +41223727385

Fax: +41223727320

E-mail: marc.fathi@hcuge.ch

aDepartment of genetic and laboratory medicine

Division of laboratory medicine, Toxicology laboratory

Geneva University Hospital

4 rue Gabrielle-Perret-Gentil

$\mathrm{CH}-1211$ Geneva 14

${ }^{b}$ ADMed Laboratoires, 20 rue de Chasseral

$\mathrm{CH}-2300$ La Chaux-de-Fonds

'School of Pharmaceutical Sciences

University of Geneva, University of Lausanne

20 Bd D'Yvoy, $\mathrm{CH}-1211$ Geneva 4

'Swiss Center of Applied Human Toxicology

University of Geneva, CMU

1 rue Michel-Servet, $\mathrm{CH}-1206$ Geneva
}

graphic separation and MS detection. This list is not exhaustive but provides an overview of the trend in LC-MS(/MS) toxicological screening.

\section{LC-MS (/MS) Methods}

LC-MS (/MS) procedures include four main steps: sample preparation, chromatographic separation, MS detection and data treatment. These aspects are mentioned in Table 1 where the column 'analytes' gives the number of compounds contained in the library used. These steps can be more or less consolidated and automated as discussed later. Even if LC-MS (/MS) systems are becoming increasingly user friendly, their use is a suitable choice from a long-term perspective only if the required expertise is present in a laboratory.

\section{Sample Preparation}

The various procedures for sample work-up mentioned in Table 1 show that there are no established or generic protocols for sample preparation in toxicological screening, but when using LC-MS (/MS), an adequate sample clean-up is required to minimize matrix effects (MEs) especially when an electrospray ionisation (ESI) source is used.

Dilute-and-shoot is exclusively used for urine samples, ${ }^{[7,10]}$ while protein precipitation (PP), ${ }^{[15]}$ liquid-liquid extraction (LLE) ${ }^{[3,6,8-11]}$ or solid phase extraction $(\mathrm{SPE})^{[3-5,11,13,16]}$ are applied to several matrices (blood, urine or gastric content). The association of PP and SPE decreases the
MEs and would be a good choice for the blood sample treatment. ${ }^{[12,17]}$

The automation of methods of sample preparation can optimise the reproducibility of the process and facilitate the use of LC-MS/(MS) techniques in clinical laboratories. The Basel group uses a Prospekt system for SPE automation. ${ }^{[12]}$ In our opinion, this instrumentation is particularly well adapted for high throughput and therefore restricted to very large medical laboratories.

Another emerging possibility is the use of a turbo flow column on-line as described in the publication of Mueller et al..$^{[14]}$ To our knowledge, this methodology has been applied only to urine samples and is probably more difficult to optimise for complex matrices such as blood.

\section{Chromatographic Separation}

In order to maintain good chromatographic performance combined with reduced analysis time, several strategies can be selected where a compromise is necessary between flow rates, column length, resolution and backpressure. A very promising strategy is the use of sub-2 $\mu \mathrm{m}$ particles with high pressure: ultra high pressure liquid chromatography (UHPLC). ${ }^{[7,9,11,13,15,18]}$

\section{Mass Spectrometry Detection}

The range of applications covered by LC-MS/MS are linked to the ion source, while the high selectivity obtained through the detection of the analyte molecular mass 
Table 1. Essential features of the different LC-MS(/MS) methods developed for toxicological screenings. The analytes content of the library used is mentioned in the 'Analytes' column.

\begin{tabular}{|c|c|c|c|c|c|c|}
\hline Sample & Work-up & Chromatographic separation & Ionization mode & $\begin{array}{l}\text { Type of mass } \\
\text { analyzer }\end{array}$ & Analytes & Reference \\
\hline $\mathrm{B}, \mathrm{U}$ & LLE or SPE & $\begin{array}{l}\text { Synergy Polar RP } \\
(150 \times 2 \mathrm{~mm}, 4 \mu \mathrm{m})\end{array}$ & ESI & QQQ/LIT & 301 & [3] \\
\hline $\mathrm{U}$ & SPE & $\begin{array}{c}\text { Luna C18 } \\
(100 \times 2 \mathrm{~mm}, 3 \mu \mathrm{m})\end{array}$ & ESI & TOF & 735 & [4] \\
\hline $\mathrm{S}, \mathrm{P}, \mathrm{U}, \mathrm{G}$ & SPE & $\begin{array}{c}\text { XTerra MS C18 } \\
(100 \times 2.1 \mathrm{~mm}, 3.5 \mu \mathrm{m})\end{array}$ & ESI & QQQ/LIT & ? & [5] \\
\hline $\mathrm{U}$ & LLE & $\begin{array}{c}\text { Discovery C18 } \\
(150 \times 2.1 \mathrm{~mm}, 5 \mu \mathrm{m})\end{array}$ & ESI & QQQ & 72 & [6] \\
\hline $\mathrm{U}$ & Dilution & $\begin{array}{l}\text { Acquity UPLC BEH C18 } \\
(100 \times 2.1 \mathrm{~mm}, 1.7 \mu \mathrm{m})\end{array}$ & ESI & TOF & 103 & [7] \\
\hline $\mathrm{B}, \mathrm{U}$ & LLE & $\begin{array}{c}\text { Gemini C18 } \\
(100 \times 2 \mathrm{~mm}, 3 \mu \mathrm{m})\end{array}$ & ESI & QQQ/LIT & 25 & [8] \\
\hline $\mathrm{U}$ & LLE & $\begin{array}{l}\text { Acquity UPLC HSS T3 } \\
(100 \times 2.1 \mathrm{~mm}, 1.8 \mu \mathrm{m})\end{array}$ & ESI & TOF & 300 & [9] \\
\hline $\mathrm{U}$ & Dilution; LLE & $\begin{array}{l}\text { Restek Allure PFP Propyl } \\
\quad(50 \times 2.1 \mathrm{~mm}, 5 \mu \mathrm{m})\end{array}$ & ESI & QQQ/LIT & 700 & [10] \\
\hline $\mathrm{B}, \mathrm{U}$ & SPE; LLE & $\begin{array}{c}\text { Zorbax SB-Aq } \\
(100 \times 2.1 \mathrm{~mm}, 1.8 \mu \mathrm{m})\end{array}$ & ESI & Ion Trap & 800 & [11] \\
\hline $\mathrm{S}, \mathrm{U}$ & $\mathrm{PP}+\mathrm{SPE}$ & $\begin{array}{l}\text { CC Nucleodur C18 } \\
(125 \times 4 \mathrm{~mm}, 3 \mu \mathrm{m})\end{array}$ & APCI & Ion Trap & 365 & [12] \\
\hline $\mathrm{S}$ & SPE & $\begin{array}{c}\text { Hypersil Gold } \\
(100 \times 2.1 \mathrm{~mm}, 1.9 \mu \mathrm{m})\end{array}$ & ESI & QQQ/LIT & 300 & [13] \\
\hline $\mathrm{U}$ & Turboflow & $\begin{array}{l}\text { Betasil Phenyl/Hexyl } \\
(100 \times 3 \mathrm{~mm}, 3 \mu \mathrm{m})\end{array}$ & APCI & Ion Trap & 356 & [14] \\
\hline $\mathrm{U}$ & PP & $\begin{array}{c}\text { Hypersil Gold C18 } \\
(100 \times 2.1 \mathrm{~mm}, 1.9 \mu \mathrm{m})\end{array}$ & ESI & Ion Trap & 700 & [15] \\
\hline $\mathrm{B}, \mathrm{U}, \mathrm{T}$ & SPE & $\begin{array}{c}\text { Hypersil Gold PFP } \\
(150 \times 2.1 \mathrm{~mm}, 5 \mu \mathrm{m})\end{array}$ & ESI & Ion Trap & 359 & [16] \\
\hline
\end{tabular}

Abbreviations: B, blood; U, urine; S, serum; P, plasma; G, gastric content ; T, tissue specimens; LLE, liquid-liquid extraction; SPE, solid-phase extraction; PP, protein precipitation; ESI, electospray ionization; QQQ/LIT, triple quadrupole/linear ion trap; TOF, time-of-flight; QQQ, triple quadrupole.

and its specific disintegration behaviour is in relation to the analyzer employed.

Electro spray ionisation (ESI) and atmospheric pressure chemical ionisation (APCI) are currently used in toxicology screening methods as shown in Table 1. Atmospheric pressure photo ionization (APPI) has not been reported for screening applications to our knowledge. [19]

APCI is less prone to ME than ESI and explains this choice of ionisation source by some laboratories. ${ }^{[12,14,20]}$ Nevertheless, fewer applications in toxicology are reported with APCI sources: ${ }^{[21,22]}$ limited polarity range, relative incompatibility with thermally labile compounds and higher background noise compared to ESI are probably the reasons for this lack of applications.

Currently APCI and ESI are often used on the same instrument and recent sources allow a rapid switch between both ionisation modes. ${ }^{[23]}$ This could be a future development of screening methods but presently, the benefit/drawback ratio of these sources does not favour their use.

The same observation applies to the switching ionisation mode positive/nega- tive. Ninety percent of relevant toxicological compounds are ionised in positive mode. Therefore the switching polarity is rarely used. Most of the publications referred to in Table 1 mention two injections, one for each polarity. This helps to maintain efficient and generic methods.

\subsection{Analyzers}

Three main types of analyzer are currently available in clinical laboratories: quadrupole (Q), ion trap (IT) and time-offlight (TOF). They can be used separately or in combination.

The $\mathrm{QqQ}_{\mathrm{LIT}}$ configuration is a particularly interesting mix of $\mathrm{Q}$ and IT.[24,25] Higher sensitivity is observed in $\mathrm{QqQ}_{\mathrm{LIT}}$ configurations compared to QqQ when the third Q is used as a LIT. This configuration was successfully implemented in general unknown screening (GUS) ${ }^{[5,26]}$ and multi-targeted screening (MTS) methods. ${ }^{[3,8,10,13,27,28]}$

The ability of TOF instruments to accurately determine $\mathrm{m} / \mathrm{z}$ of a particular compound enables the attribution of a unique formula based on constituent atoms. This approach means that spectral libraries can be generated from the molecular formula without the need for reference material and explains the growing interest for this instrument type. ${ }^{[29,30]}$ However, exact mass alone does not provide unequivocal identification of compounds as shown in publications listed in Table 1. ${ }^{[31]}$ Ojanpera et al. evaluate the influence of isotopic pattern in addition to accurate mass measurement and retention time for the identification of compounds. ${ }^{[4]}$ In this study the isotopic pattern revealed on average $12 \%$ fewer false positive entries than using accurate mass only. The methodology developed by Badoud et al. is a procedure in three stages. ${ }^{[7]}$ This method includes screening, pre-confirmatory and confirmatory steps. Retention time and exact mass are considered in the screening step. MS/MS data are acquired in the pre-confirmatory step for a specific retention time after reinjection of the sample. The confirmatory analysis includes a dedicated SPE extraction and analysis in tandem mode to obtain exact mass on precursor and characteristic product ions. ${ }^{[32]}$ In the third screening publication using a TOF mass analyser, the identification is based on a combination of 
retention time, exact mass and fragmentation pattern. [9]

The combination UHPLC-TOF is very promising for toxicological screening in order to shorten analysis time whilst keeping high resolution. ${ }^{[7,9,33]}$

MS-MS offers enhancement of selectivity which allows full exploitation of LCMS. Targeted methods mainly use the multiple reaction monitoring (MRM) mode. In this process, different reactions (precursor ion $\rightarrow$ product ion) are monitored. This mode offers high selectivity of detection with high sensitivity. ${ }^{[6,34,35]}$ Similar MSMS procedures can also be implemented in IT instruments. The sequential steps can be repeated $n$ times by trapping different product ions each time, so that $\mathrm{MS}^{\mathrm{n}}$ can be carried out. Often, $n$ does not exceed $2^{[11,12,16]}$ or 3 due to a loss of signal. ${ }^{[14,15,36]}$ In both of these methods, detection is restricted to the list of compounds included in the initial research list (MRM or pseudomolecular ion). In GUS applications, each signal higher than a predefined threshold is considered for subsequent experiments. In this case the identification capacity is restricted to the content of the library data base used.

Orbitrap, introduced on the market in 2005 , is similar to the ion trap but the detection is not performed by ion ejection. As with TOF instruments, Orbitrap affords accurate mass determination and can be used in hybrid configuration. It also allows a higher resolution but the scan rate is lower compared to a TOF instrument. ${ }^{[37]}$ The use of such systems for forensic toxicology seems very promising. ${ }^{[38,39]}$

\section{Use in a Clinical Laboratory}

A broad spectrum screening panel is necessary to cover drugs and substances that may have clinical significance for patients who remain intoxicated and occasionally comatose. Moreover, toxicological data may impact on the efficiency of emergency department (ED) triaging decisions, with important implications for healthcare costs.

There is increasing utilisation of LCMS and LC-MS/MS to complement GCMS and LC-UV for screening. We consider the identification by the tandem use of MS to be more secure than single MS or LC-UV, as proposed by K. Lynch. ${ }^{[16,40]}$

A major issue is the lack of commercial, universally applicable libraries for LC-MS (/MS). ${ }^{[41,42]}$ Whilst several libraries have been established (an ESI-MS/MS library of 800 compounds obtained on triple quadrupole; ${ }^{[43]}$ a library containing 1253 compounds obtained on a quadrupole linear ion trap $\left.{ }^{[27]}\right)$, they are instrument dependent and very restrictive in comparison to GC-MS libraries. ${ }^{[44,45]}$ Moreover, optimal results require acquisition of a spectrum under conditions identical to those used to create the library. ${ }^{[46]}$ In addition, the number of compounds stored in the library limits the identification capacity of an analyser.

The selectivity of tandem MS detection minimizes the number of false negative and positive results as far as data review criteria are established. Three of the most common criteria (as proposed by Rivier ${ }^{[47]}$ ) used for positive identification and frequently mentioned in screening methods ${ }^{[13,48]}$ are: a) retention time relative to the internal standard should be very close to that expected; b) acquired spectra match the library spectra with a high score and c) at least three matching ions between the acquired and library spectra. ${ }^{[13,40]}$

Guidelines for qualitative analytical toxicology analysis have been published[48-50] based on the principle of sequential investigations (from screening to confirmatory analysis). Economic considerations of such a strategy are that each time an immunoassay is used to screen a compound family (benzodiazepines, opiates,...) a confirmatory or identification test will be needed as immunoassays have a low specificity. MS will allow detection and identification of drugs in the first instance with high selectivity and sensitivity for a broad panel of compounds. The limitations of the chosen method being known, complementary testing can be performed. $[7,49,50]$

Today, two general approaches are emerging. ${ }^{[51]}$ The first uses triple quadrupole, ion trap or hybrid mass spectrometers to generate information-rich product ion spectra (Fig. 1). The second relies on highresolution mass spectrometry with benchtop TOF mass spectrometers

\section{Conclusion and Perspectives}

Screening of a wide variety of compounds from several matrices is a demanding task, but LC-MS proves to be amenable to such applications. General unknown screening procedures can be defined as analytical techniques or combinations of analytical techniques aimed at detecting and identifying unknown compounds in biological fluids. Comparison of results

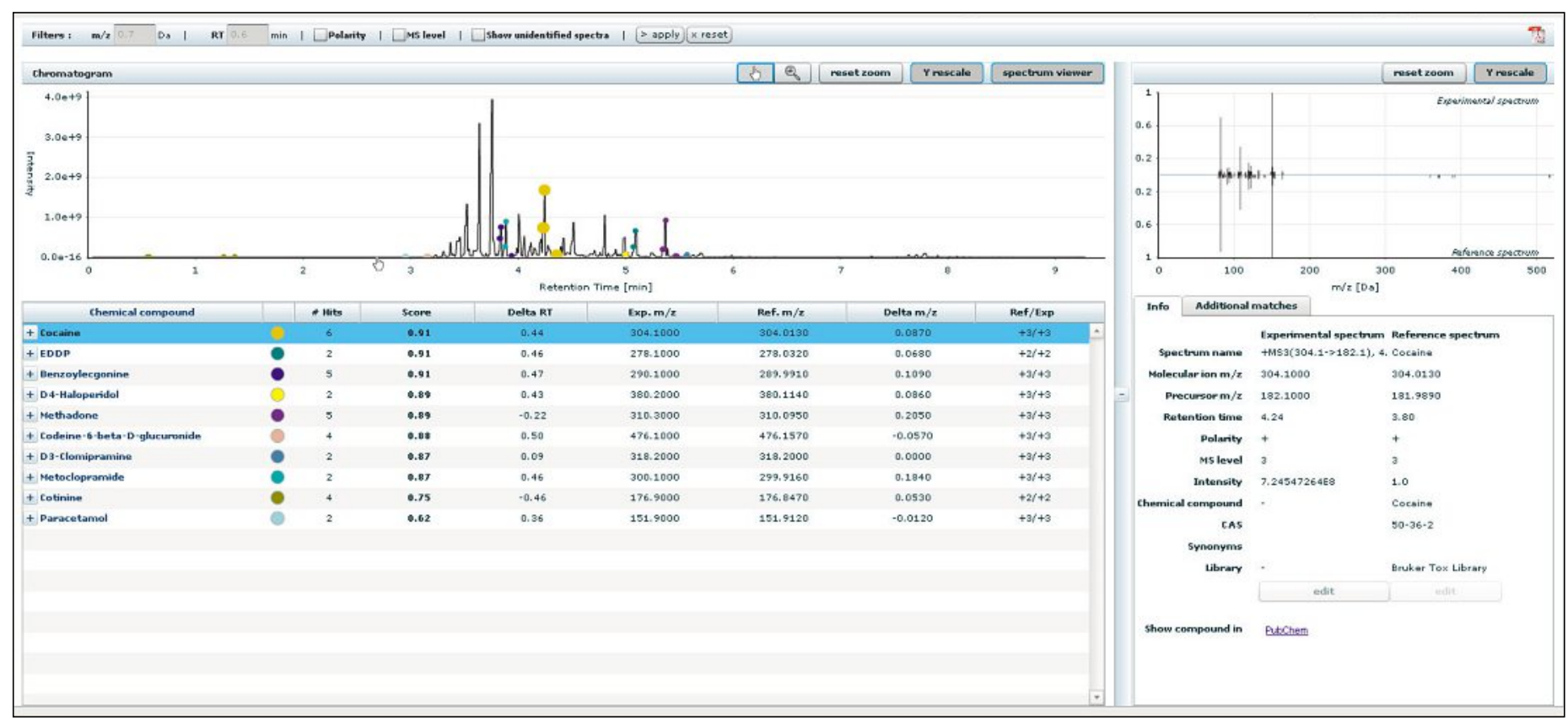

Fig. 1. Representative multi-target screening of a patient sample analyzed by LC-lon Trap/MS/MS and processed for identification by SmileMS software (by permission of Toxicology Laboratory / Geneva University Hospitals). 
reveals that LC-MS and GC-MS are both valuable tools for the characterization of drugs. Nevertheless, neither technique was able to detect and identify all compounds present in samples. ${ }^{[52]}$ Hence, the use of complementary techniques is the best approach for 'general unknown screening'.

It is probable that high-resolution MS paired with MS-MS spectra will be increasingly used for screening methods in order to improve the accuracy of identifications. Moreover, mass spectrometer performance will evolve via enhanced sensitivity, selectivity, scan speed and mass accuracy. This will favour the spread of LC-MS in analytical toxicology laboratories.

Furthermore, MS-MS sensitivity promotes a growing interest for alternative sample preparation such as dried blood samples (DBS). ${ }^{[53]}$

\section{Acknowledgments}

The authors wish to acknowledge Dr. Séverine Hughes and Prof. R. James for reviewing the manuscript.

Received: February 29, 2012

[1] M. Vogeser, C. Seger, Clin. Biochem. 2008, 41, 649.

[2] P. J. Taylor, Ther. Drug Monit. 2005, 27, 689.

[3] C. A. Mueller, W. Weinmann, S. Dresen, A. Schreiber, M. Gergov, Rapid Commun. Mass Spectrom. 2005, 19, 1332.

[4] S. Ojanperä, A. Pelander, M. Pelzing, I. Krebs, E. Vuori, I. Ojanperä, Rapid Commun. Mass Spectrom. 2006, 20, 1161.

[5] F. L. Sauvage, F. Saint-Marcoux, B. Duretz, G. Lachâtre, P. Marquet, Clin. Chem. 2006, 52, 1735.

[6] M. Mazzarino, X. de la Torre, F. Botrè, Anal. Bioanal. Chem. 2008, 392, 681.

[7] F. Badoud, E. Grata, L. Perrenoud, L. Avois, M. Saugy, S. Rudaz, J. L. Veuthey, J. Chromatogr. A 2009, 1216, 4423 .

[8] M. Gergov, P. Nokua, E. Vuori, I. Ojanperä, Forensic Sci. Int. 2009, 186, 36.

[9] H. K. Lee, C. S. Ho, Y. P. H. Iu, P. S. J. Lai, C. C. Shek, Y.-C. Lo, H. B. Klinke, M. Wood, Anal. Chim. Acta 2009, 649, 80.
[10] S. Dresen, N. Ferreirós, H. Gnann, R. Zimmermann, W. Weinmann, Anal Bioanal Chem. 2010, 396, 2425.

[11] H.-C. Liu, R. H. Liu, D.-L. Lin, H.-O. Ho, Rapid Commun. Mass Spectrom. 2010, 24, 75.

[12] S. Sturm, F. Hammann, J. Drewe, H. H. Maurer, A. Schole, J. Chromoatogr. B 2010, 878, 2726.

[13] V. Viette, D. Guillarme, R. Mylonas, Y. Mauron, M. Fathi, S. Rudaz, D. Hochstrasser, J. L. Veuthey, Clin. Biochem. 2011, 44, 45.

[14] D. M. Mueller, B. Duretz, F. A. Espourteille, K. M. Rentsch, Anal. Bioanal. Chem. 2011, 400, 89.

[15] D. K. Wissenbach, M R. Meyer, D. Remane, A. A. Weber, H. H. Maurer, Anal. Bioanal. Chem. 2011, 400,79

[16] R. D. Johnson, S. R, Botch, J. Anal. Toxicol. 2011, 35, 65 .

[17] I. Marchi, S. Rudaz, M. Selman, J. L. Veuthey, J. Chromatogr. B 2007, 845, 244.

[18] D. Guillarme, D. T. T. Nguyen, S. Rudaz, J. L. Veuthey, J. Chromatogr. A 2007, 1149, 20.

[19] I. Marchi, S. Rudaz, J. L. Veuthey, Talanta 2009, 78, 1.

[20] R. Dams, M. A. Huestis, W. E. Lambert, C. M. Murphy, J. Am. Soc. Mass Spectrom. 2003, 14, 1290.

[21] C. Kratzsch, O. Tenberken, F. T. Peter, A. A. Weber, T. Kraemer, H. H. Maurer, J. Mass Spectrom. 2004, 29, 856.

[22] H. H. Maurer, T. Kraemer, C. Kratzsch, F. T. Peters, A. A. Weber, Ther. Drug Monit. 2002, 24, 117.

[23] J. Schappler, R. Nicoli, D. Nguyen, S. Rudaz, J. L. Veuthey, D. Guillarme, Talanta 2009, 78, 377.

[24] G. Hopfgartner, E. Varesio, V. Tschappat, C. Grivet, E. Bourgogne, L. A. Leuthold, J. Mass Spectrom. 2004, 72, 3653.

[25] S. Smith, C. Giesker, R. Reimschuessel, C. S. Decker, M. C. Carson, J. Chromatogr. A 2009, 1216,8224 .

[26] P. Marquet, F. Saint-Marcoux, T. N. Gamble, J. C. Leblanc, J. Chromatogr B 2003, 789, 9.

[27] S. Dresen, M. Gergov, L. Politi, C. Halter, W. Weinmann, Anal. Bioanal. Chem. 2009, 395, 2521.

[28] J. W. Hager, Rapid Commun. Mass Spectrom. 2002, 16, 512 .

[29] S. Lak, A. Pelander, E. Vuori, E. Ali-Tolppa, E. Sippola, I. Ojanperä, Anal. Chem. 2004, 76 , 7375.

[30] M. Gergov, B. Boucher, I. Ojanperä, E. Vuori, Rapid Commun. Mass Spectrom. 2001, 15, 521.

[31] A. Pelander, I. Ojanperä, S. Laks I. Rasanen, E. Vuori, Anal. Chem. 2003, 75, 5710.
[32] F. Badoud, E. Grata, L. Perrenoud, M. Saugy, S. Rudaz, J. L. Veuthey, J. Chromatogr. A 2009. $1216,4423$.

[33] M. Wood, M. Laloup, N. Samyn, M. M. el Mar Ramirez Fernandez, E. A. de Bruijn, R. A. A. Maes, G. De Boeck, J. Chromatogr. A 2006, 1130,3 .

[34] A. M. Rodrigues, V. Ferreira, V. V. Cardoso, E. Ferreira, M. J. Benoliel, J. Chromatogr. A 2007, 1150, 267.

[35] M. Gergov, I. Ojanperä, E. Vuori, J. Chromatogr. B 2003, 795, 41 .

[36] R. L. Fitzgerald, J. D. Rivera, D. A. Herold, Clin. Chem. 1999, 45, 1224.

[37] J. L. Habib Jiwan, P. Wallemacq, M. F. Hérent, Clin. Biochem. 2011, 44, 136.

[38] K. J. McHale, M. Sanders, Thermo Scientific Application Brief \#10.

[39] K. Johnson, M. Kozak, Thermo Scientific Application Note \#489b.

[40] K. L. Lynch, A. R. Breaud, H. Vandenberghe, A. H. B. Wu, W. Clarke, Clin. Chim. Acta 2010, $411,1474$.

[41] R. Jansen, G. Lachatre, P. Marquet, Clin. Biochem. 2005, 38, 362 .

[42] D. K. Wissenbach, M. R. Meyer, A. A. Weber, D. Remane, A. H. Ewald, F. T. Peters, H. H. Maurer, J. Mass Spectom. 2012, 47, 66.

[43] S. Dresen, J. Kempf, W. Weinmann, Forensic Sci. Int. 2006, 161, 86.

[44] 'Mass spectral library of drugs, poisons, pesticides, pollutants and their metabolites', $5^{\text {th }}$ rev. ed., Eds. H. H. Maurer, K. Pfleger, A. Weber, Weinheim, Wiley-VCH, 2011.

[45] F. W. McLafferty, 'Wiley registry of mass spectral data', $6^{\text {th }}$ ed., Wiley, New York, 1997.

[46] J. L. Josephs, M. Sanders, Rapid Commun. Mass Spectrom. 2004, 18, 743.

[47] L. Rivier, Anal. Chim. Acta 2003, 492, 69.

[48] The Alberta Clinical Practice Guidelines Program. Laboratory guideline for the investigation of the poisoned patient. http:// www.albertadoctors.org/resources/cpg/ toxicology-guideline.pdf, 1999

[49] A. H. B. Wu, C. McKay, L. A. Broussard, R. S. Hoffman, T. C. Kwong, T P. Moyer, E. M. Otten, S. L. Welch, P. Wax, Clin. Biochem. 2003, 49, 357

[50] J. P. Goullé, M. Lhermitte, M. Batholi, J. C. Boyer, B. Capolaghi, C. Charlier, V. Danel, G. Desch, A. Feuillu, B. Flouvat, D. Mathieu, P. Nisse, N. Sadeg, A. Szymanowicz, Annal. Biol. 2003, 61, 421.

[51] F. T. Peters, Clin. Biochem. 2011, 44, 54.

[52] H. H. Maurer, Anal. Bioanal. Chem. 2007, 388, 1315

[53] A. J. Wilhelm, J. C. de Burger, R. M. Vos, A. Chahbouni, A. Sinjewel, J. Chromatogr. B 2009, 877, 1595 . 